\title{
La «barbarie» moderna, ¿un microestado de la naturaleza?
}

\section{Claus Offe*}

Hertie School of Governance

Berlín

\section{Resumen}

En este trabajo, el autor introduce una importante consideración en el análisis de la barbarie. A su juicio, no hay únicamente una constelación dicotómica con un sujeto actor, el perpetrador, y un sujeto paciente, la víctima, sino una constelación triangular en la que se desoculta al espectador que calla u omite, insensibilizado moralmente, las acciones que «más allá del bien y del mal» realiza el perpetrador contra la víctima.

Palabras clave: barbarie, modernidad, perpetrador, víctima, espectador.

\section{Abstract Modern Barbarism: A Microstate of Nature?}

In this paper the author introduces one important consideration related to the analysis of barbarity. According to him there is no only one two sided constellation shaped by the acting subject, the perpetrator, and an subject transformed in an object upon which is done violence, the victim, but a "triangular" constellation in which the observer, morally neutralized, who wilfully forgets actions that «beyond good and evil" does the perpetrator against the victim, is unhide.

Key words: barbarity, modernity, perpetrator, victim, observer.

\section{Sumario}

1. Diferenciación entre dos tipos de barbarie

2. Examen del segundo tipo: macrofenómenos y microfenómenos
3. Perfil de tres hipótesis sobre la ocurrencia de «microestados de naturaleza»

En los diccionarios y libros de referencia especializados, el término barbarie casi no aparece, y aún menos en los de ciencias sociales. Las explicaciones de su etimología muestran una semántica lo suficientemente ramificada. En el uso primitivo griego de los escritos de Homero y Heródoto, los bárbaros eran gente de

* El autor desea reconocer las útiles sugerencias que ha recibido de Hartmut Diessenbacher, Susanne Fuchs, Ulrich K. Preuss, Volker Schmidt y Michael Zuern. 
lengua extranjera - extranjeros lingüísticos con quienes no nos podemos comunicar, ni en su lengua ni en la nuestra. Aquí los griegos pensaban en los habitantes de Asia Menor, especialmente en los persas. Al principio, la rareza del idioma y las creencias religiosas como distintivos de una forma de vida bárbara no se veían con desprecio. De hecho, como destaca un lingüista, en las obras de Homero y Heródoto se puede percibir una "propensión especial a idealizar a los bárbaros». El apóstol Pablo (ICor 14:11) amonesta a la comunidad contra los «habladores de lenguas» y los compara con bárbaros ("gente de naciones del todo extrañas»). Con esto se está refiriendo a todos los excéntricos religiosos que adoran a Dios en una lengua más bien individual y privan al resto de creyentes de experimentar «la edificación moral» y el "conocimiento espiritual», minando así la comunidad de creyentes.

No es hasta el tiempo de Jerjes, y durante las confrontaciones militares entre los griegos y los persas, que la expresión bárbaros toma en griego una connotación negativa. A partir del siglo IV aC, la palabra adopta un significado definido para adjetivos como incivilizado, inculto, salvaje (tanto primitivo como feroz), ignorante, extranjero, cruel e inhumano.

En la Roma imperial, el bárbaro es, en parte, el equivalente a un trabajador militar extranjero: los bárbaros eran mercenarios reclutados en las provincias extranjeras del imperio y en sus nationes.

Esta esfera de significación se redescubre especialmente en Francia, a través de una antropología política pesimista, a comienzos de la modernidad, inspirada en imágenes de la antigüedad clásica, y se introduce después en el discurso filosófico, legal y estético. Baudelaire trata detalladamente la cuestión del «eternelle et incurroegible barbarie de l'homme», y la vigilia de la Primera Guerra Mundial, los socialistas (Jeran Jaurès, y después Rosa Luxemburgo) se manifiestan bajo el grito de batalla «socialisme ou barbarie». A su vez, el Código Penal francés prevé sentencias más duras cuando una agresión contra la vida y la integridad física se ejecute de manera «bárbara», es decir, «empleando tortura corporal» ${ }^{1}$.

A través de este uso francés del siglo XIX y de principios del XX, el concepto de barbarie se abrió camino, a gran escala, en el lenguaje de la historia contemporánea alemana y en su interpretación tras la Segunda Guerra Mundial. Aquí llega a significar la máxima antítesis de la supuesta condición normal de la civilización y la modernidad, sobre todo tras la aniquilación metódica de los judíos durante la guerra.

1. Para hacerlo más confuso, la expresión Berberie o Barbarei (o en catalán Barbària) en francés y alemán antiguo se usa como término geográfico para los países del Norte de África habitados por los bereberes (Libia, Tunicia, Argelia, Marruecos). Este término usado para designar a los nativos norteafricanos, que aún hoy son seminómadas, y los asentamientos de los cuales fueron colonizados por los árabes en el siglo VII, se remonta a una raíz arábiga (barbar). Es interesante señalar que, en alemán, la palabra berber es también el término que usan (orgullosos) para describirse a sí mismos los vagabundos no residentes de la ciudad y del campo, asunto, sin duda, etimológicamente y semánticamente misterioso. 
La hipótesis implícita, y de máximo interés para las ciencias sociales, ofrece un panorama oscuro de la civilización: el aumento de los adelantos pasados de la civilización incrementa no solamente la posibilidad de caer en la barbarie - por el motivo lógico y trivial de que ha aumentado la altura de una caída potencial—, sino también la probabilidad empírica de la misma caída, por razones que permanecen desconcertantemente misteriosas. Desde esta visión, de la cual Adorno y Bauman son partidarios destacados, la barbarie y la civilización emergen como componentes mutuamente constitutivos de contradicciones dialécticas ${ }^{2}$.

Aquello que los científicos sociales pueden conseguir se limita al esfuerzo de introducir la distinción conceptual. Con esto no se esperan «soluciones», sino, como mucho, explicaciones parciales. Por encima de todo, mediante la elaboración de distinciones sólidas, esperan poder ejercer una influencia favorable sobre el nivel del debate, tan académico como extraacadémico. Así, intentaré (1) diferenciar entre dos tipos de barbarie, (2) examinar macrofenómenos y microfenómenos dentro del segundo tipo y (3) perfilar cinco hipótesis sobre la existencia de «microestados de la naturaleza».

\section{Diferenciación entre dos tipos de barbarie}

Una lectura atenta de 540 títulos de libros que contienen la palabra barbarie, y que se publicaron durante los siglos XIX y XX en varias lenguas europeas, nos trae - aparte (y mucho antes) del caso, para nosotros, paradigmático: los asesinatos en masa cometidos por el Estado nazi- en la siguiente (muy incompleta) lista de condiciones, fenómenos, épocas y actos calificados de «bárbaros» por los correspondientes autores.

— La calidad estética del mobiliario de los hospitales y otras instituciones públicas.

- Anarquismo.

- Antisemitismo.

- Civilización azteca.

- Guerra de los Boers.

- Bolchevismo.

- Guerra civil en general, Bosnia en particular.

- Gobierno colonial.

- Castigo corporal («garrotazos») en la aplicación de la ley de la República de Singapur.

- Crueles condiciones de encarcelamiento.

- La pena de muerte.

2. Ésta es claramente una tesis que se considera, debido a su misma radicalidad, poco interesante, porque si sus defensores tenían razón en la afirmación determinista de que la modernización de la civilización era un programa inexorablemente autodestructivo, siendo totalmente inútil cualquier intento de tomar contramedidas, ¿qué quedaría para debatir? 
- La ignorancia de las leyes gramaticales.

- La historia primitiva de la raza humana (Morgan).

- Ecocidio.

- Galicismos de la lengua castellana («una lengua que se corrompe es siempre indicio de una sociedad corrompida»).

- Leyes dietéticas judías.

- Megaciudades.

- Militarismo.

- Dictadura militar en Argentina.

- Pasos y medidas no métricas.

- Dieta no vegetariana («la carne es un asesinato»).

- Paganismo.

- La política cultural de los alemanes del Este tras 1990.

- Poligamia

- La práctica o tolerancia del aborto.

- Protestantismo.

- Racismo.

- Restricción del comercio libre a través de aranceles proteccionistas.

- Esclavitud.

- Discriminación estatal de la homosexualidad.

- Terrorismo.

- Totalitarismo.

- Moralidad sexual victoriana.

- Crímenes de guerra.

- Tácticas militares del indio americano.

- El siglo XX.

Aquello que tienen en común estos fenómenos es, como mucho, su referencia a la violación, destrucción o desatención de categorías de integridad física y simbólica y de identidad cultural. Los «bárbaros» parecen diferentes, traen ropa diferente y comen comida extraña, siguen otras normas sexuales, viven en un lugar lejano, hablan una lengua diferente, etc.; o bien las normas relativas a la integridad física y simbólica, válidas para nosotros, són violadas, de forma especialmente «cruel», «salvaje» o «violenta», por su comportamiento. El concepto de bárbaro marca una dura discrepancia entre «nosotros» y «ellos», y se opone a «su» violación de «nuestros» estándares culturales y estéticos mínimos.

De todos modos, barbarie no es un término muy usado en teoría social, y, debido a la gran variedad de aplicaciones (como lo ilustra la lista de arriba), no está claro si un intento de afilarlo conceptualmente con finalidad analítica sería demasiado útil. Al contrario, parece que nos encontramos en un término resumen para aquello que el observador correspondiente quiere designar como el «más allá» de la vida social tal y como él la conoce, parecido a un simple eslogan passe-par-tout para conseguir una exageración negativa. Esta sospecha, no obstante, se desvanece en el momento que nos damos cuenta que, al inten- 
tar clasificar los fenómenos «bárbaros», surge una bifurcación sorprendentemente clara. Podemos hablar de un uso «externo» e "interno» del término —o de una barbarie antes de la civilización y de otra después.

1. En el uso externo, los bárbaros son aquellos que «no son de los nuestros». La lógica binaria del término es que excluye la interacción y rehúsa las normas de reciprocidad hacia los «bárbaros», que no toman parte en la civilización del que usa este término ${ }^{3}$. Los bárbaros son aquéllos con quienes tan sólo es permitido un contacto muy selectivo. Nuestra lengua y nuestras costumbres les son ajenos, como lo son las suyas para nosotros. $\mathrm{Si}$, no obstante, hubiera contacto, tendrá que ser, a la fuerza, desorganizado. No se tienen que esperar más contactos; no hay ningún deseo de más encuentros. Por lo tanto, se puede tratar a los «bárbaros» no como gente, sino como «objetos» - ya sea convirtiéndolos en objetos de los esfuerzos educativos misioneros de la civilización o creyéndose uno mismo con el derecho de ignorar los derechos y la vulnerabilidad física. Los bárbaros son aquéllos que no nos interesan. Los «bárbaros» son un fenómeno histórico y geográfico: su hogar es en otro lugar, en un lugar muy lejano. O bien, pertenecen - especialmente desde el punto de la teoría evolutiva - a una época remota, al principio de la historia humana. Aquí, barbarie es siempre sinónimo de señalar puntos en el espacio y en el tiempo cuando «nuestras» ideas de civilidad no tenían o no tienen validez (aún). Si este lugar, que está situado más allá de «nuestro» territorio, se descubre, se entra y se coloniza, siempre se puede concebir la aniquilación física de los «nativos». Con respecto a los derechos de propiedad de la tierra, su territorio pasa a ser terra nullius. Los bárbaros son el nada social, los gooks ('vietnamitas') de películas sobre el Vietnam como Platoon.

2. La diferencia que el concepto de barbarie marca siempre entre la primera y la tercera personas del plural permanece intacto, incluso cuando la cuestión en juego es el mismo grupo que, en un momento determinado («nosotros»), fija y defiende los estándares civilizados y en otros momentos («ellos»), en cambio, traiciona aquellos estándares como si nunca hubieran existido. Cuando se usa «internamente», por ejemplo, de una manera reflexiva e histórica, el término hace referencia a la abdicación de la civilidad, a una recaída repentina ${ }^{4}$. Bárbaros son todos los que olvidan y traicionan las premi-

3. Theodor W. Adorno («Erziehung nach Auschwitz», Stichworte, Frankfurt: Surkamp, 1969, 87) vio que el peligro de la barbarie entre la población rural era mayor que en las ciudades, y le preocupaban las iniciativas para la "desbarbarización del campo». El mismo tema de "desurbanización» como fuente para la barbarie se puede encontrar en Max WEBER, «Die Sozialen Gründe de Untergangs der “antiken” Kultur», Gesammelte Aufsätze zur Sozial —und Wirtschaftsgeschichte (Tübingen, Mohr, 1924, 289-311).

4. Una asimetría entre el proceso de civilización y descivilización consiste aparentemente en el hecho que el primer proceso sigue su curso lenta y firmemente, mientras que el segundo sucede de pronto y de manera abrupta. Cfr. Stephen Mennel, «Decivilizing Processes: Theoretical Significance and Some Lines of Research», International Sociology, 5: 2, 1990: 205-223. 
sas normativas de pertenecer a una determinada comunidad. Estas premisas consisten en el pretendido deber de ignorar y reforzar, al menos hasta cierto punto, la alteridad del otro. Este deber es violado, por ejemplo, por los medios de castigo "bárbaros»: por el simple hecho de que alguien muestre determinados rasgos o haya cometido actos incriminadores es - permanentemente $\mathrm{o}$, de forma humillante, físicamente o simbólicamente- expulsado de la comunidad legal y social de personas respetables, y tratado como un objeto extraño. En este significado "interno», los bárbaros son aquéllos que consideran y tratan a los otros como bárbaros (en el sentido «externo" perfilado antes), aunque hayan establecido algún tipo de relación social con ellos - una relación real y legal de pertenencia a una comunidad reconocida previamente por ambas partes. (Para ilustrarlo, podemos pensar en el alto nivel de matrimonios mixtos que existía entre serbios y croatas antes de la guerra civil de la antigua Yugoslavia.)

En este sentido, la barbarie es un ahora y aquí, no es un fenómeno lejano en el espacio o distante en el tiempo. Y es un fenómeno moderno en cuanto que los fenómenos modernos del Estado nacional y del mercado laboral, del comercio internacional y de los regímenes transnacionales, de la globalización de la cultura y la comunicación han puesto los fundamentos de alguna medida de inclusión global. Es sólo en este «moderno» nivel de inclusión que la ocasión y la tentación por cometer actos bárbaros, es decir, de exclusión «interna», emerge - para revocar un ya transitado terreno común de lengua, derechos y costumbres ${ }^{5}$. En un mundo donde ya no hay naciones "salvajes», aquéllos que practican la exclusión interna ${ }^{6}$ cuando declaran extranjeros inútiles a los miembros de la comunidad, acontecen bárbaros.

Por lo tanto, por lo visto, podemos distinguir dos constelaciones en las que tiene lugar el concepto de «bárbaro» o «barbarie»:

- Primero, bárbaros son los radicalmente otros — nuestra relación hacia ellos es de extrañeza lingüística y de imposibilidad de comunicación, y «nuestra» opinión de estos extranjeros, en lugar de totalmente negativa, al menos en un principio, es ambivalente. Al principio, no hay demasiadas razones por tener una opinión definitiva, mientras el contacto con los extranjeros sea accidental y de naturaleza no rutinaria. Los extranjeros acontecen inferiores, o incluso enemigos, cuando "nos» atacan o cuando se oponen a

5. Weber («Die sozialen Gründe», 289) hace referencia a la «barbarie que hace tiempo ha ganado una batalla desde dentro", un "comienzo endógeno de la cultura», una "autodisolución interna de una cultura antigua», y así sucesivamente. Por lo tanto, la «barbarie» es aquí el resultado de la degeneración y del fracaso.

6. Walter Benjamin (Gesammelte Schriften II: 1, Frankfurt, Suhrkamp, 213 y s.) sugiere un concepto de barbarismo que hace énfasis en la extirpación de las sociedades modernas de sus tradiciones históricas y artísticas; según él, el barbarismo se centra en un presente en que se han proscrito todas las trazas del pasado. 
nuestros afanes expansionistas. «Nuestras» normas civiles no nos prohíben aniquilarlos militarmente y físicamente, precisamente porque las víctimas de la aniquilación no comparten estas normas y, por lo tanto, están fuera del ámbito protegido por nuestras normas.

- Segundo, nosotros «mismos» nos volvemos bárbaros si desaprendemos, por decirlo así, nuestra propia lengua. Los bárbaros son las partes extirpadas de nuestro yo colectivo, el cual — a pesar del estado de interdependencia, igualdad legal e interés compartido logrado- condena y trata a los otros como «salvajes» (ya sea por acción o por omisión). Este concepto interno de barbarie sugiere, a la vez, una constelación «triangular» de observador, perpetrador y víctima: nosotros, los observadores, tratamos (por ejemplo, con actitud crítica o de arrepentimiento) a los otros (perpetradores) como violadores (es decir, bárbaros), porque han violado las normas de algún contrato social existente en relación con el tercer grupo (las víctimas). De este modo, el concepto de bárbaro evidentemente ha cambiado de lugar dentro del plan de acción. Los bárbaros nos son los extranjeros, los de las costumbres crueles. Los bárbaros son aquéllos que, como resultado de un proceso de aprendizaje regresivo y negativo, conculcan un estado de civilización bien logrado, y tratan a los otros, que para nada son linderos, «ajenos» o «crueles», como si lo fueran. Los bárbaros modernos son quienes declaran a los otros, con todo lo que esto conlleva, bárbaros premodernos.

Lo que sucede en este último caso es el entumecimiento del sentido por una inadmisibilidad fundamental de acciones y omisiones ${ }^{7}$ que violan la integridad física y simbólica de otros a quienes, como participantes de facto en un sistema social de interacciones y normas, se les reconoce el perfecto derecho a ser protegidos por estas normas. Por «barbarie» moderna entendemos una insensibilidad especial ante la violación de las normas, una indiferencia hacia los derechos de la otra gente a la integridad y al reconocimiento que «actualmente» prevalece. En este sentido, no tan sólo las acciones, sino también las omisiones, pueden ser «bárbaras» —y no solamente el caso prototípico de negligencia, sino también el del no reconocimiento de los hechos ${ }^{8}$. La gente y los hechos que sí nos conciernen en nuestro mundo vital son entonces trasladados caprichosamente al terreno de la rareza o la insignificancia; la complicidad oculta de los peatones pasivos (aunque «miren hacia otro lado», vio-

7. La inclusión de las «acciones negativas» (omisiones) en el terreno de los fenómenos «bárbaros» es justificable por el hecho que toda sociedad tiene una matriz de utilidad legalmente o, como mínimo, moralmente obligatoria y de obligaciones a tener en cuenta y actuar en consecuencia ("moralidad existente»). Estas acciones pueden ser violadas por la inacción específica. Cfr. Sudán JameS, «The Duty To Relieve Suffering», Feminism and Political Theory, ed. Cass R. Sunstein, Chicago, University of Chicago Press, 1990, 272.

8. Hannah AREndT, «Besuch in Deutschland», Zur Zeit. Politsche Essays, Berlín, Rotbuch, 1986, 1950, 43-70. 
lando así lo que podríamos denominar el «deber de saber» social), pertenece a los fenómenos que se han denominado «barbarie moderna».

Bien seguro que no podemos averiguar a ciencia cierta si las incontables atrocidades del «segundo» y del «tercer» mundos sobre las que se informan estos días son, desde la perspectiva de los participantes, vividas como una barbarie en el sentido premoderno o en el moderno. ¿Es la erupción del odio violento contra los extranjeros lingüísticos y religiosos en sus sociedades correspondientes vista como una «ley natural» inedulible de la vida social que se tiene que sufrir con una firmeza fatalista? ¿O se ve como una recaída, acompañada de sentimientos de pena y remordimiento, de las normas de civilidad - sobre las que, desde una perspectiva interior, existe, al menos, la opinión extendida de que podrían y tendrán que ser una propiedad compartida de todos los miembros de la comunidad? En contra de la primera propuesta, se podría sostener que no tiene sentido presuponer la aplicabilidad de patrones de la cultura occidental material (por ejemplo, la electrificación) allí donde se esperarían fuerzas fundamentales duraderas e incontrolables de agresión «incivil» dirigida a (o emanando de) la prevalencia de grupos de extranjeros. Por lo tanto, cualquiera que trabaje desde una perspectiva parecida de la modernización técnica, demuestra que considera la sociedad a la que pertenece esta perspectiva como ya civilizada o al menos como potencialmente civilizable. Cualquiera que considere seriamente que la construcción del ferrocarril, la educación obligatoria, los servicios de salud y los derechos de propiedad son pasos deseables para la modernización, sólo lo puede hacer si va más allá de la semántica premoderna y "externa» del bárbaro. En este sentido, el siguiente argumento alarmantemente popular (aplicado, por ejemplo, en relación con Bosnia) también tiene que ser puesto en entredicho: aquello que, desde nuestra perspectiva civilizada, sería considerado una recaída en la barbarie si pasara «aquí», «allí» tan sólo es el efecto continuo de aquello que «ellos» nunca han conseguido vencer — la gris vida cotidiana de la historia precivilizada. Aquél que lucha por conseguir el «desarrollo», afirma así compartir no sólo elementos cognitivos de la civilización mundial, los estándares de la racionalidad tecnológica y económica; sino que se compromete, al menos implícitamente, y más allá de diferencias culturales y religiosas, a estándares y a derechos humanos igualmente universales. Porque, ¿qué sentido tiene querer mejorar las expectativas de vida de grandes grupos de personas a la vez que sus vidas son tratadas como inútiles según las guerras tribales? Claro está que las dos partes de aquello que entendemos por "civilización», la tecnológica y la moral, pueden, a sus ritmos de progreso correspondientes, deshacerse y, con el "progreso" de la tecnología militar, convertirse en antinómicas la una con la otra. Pero, inevitablemente, estas antinomias colocan en la agenda de los gobiernos nacionales y de las organizaciones internacionales el problema sobre cómo la difusión de tecnología racional (militar) y su aplicación se pueden disciplinar mediante la difusión de estándares de civilidad.

Si existiera una «sociología del mal», tendría que diferenciar, al menos, de entre las siguientes cuatro manifestaciones externas de su objeto, tal y como 
se han formado en la discusión filosófica entre Kant («Religion Within the Limits of Reason Alone») y Hegel ${ }^{9}$. Primero, el sencillo caso de la desviación ordinaria, es decir, la violación de normas que, pese a ser violadas, continúan («contrafactualmente») siendo válidas. Segundo, el caso de la ideología, es decir, el uso estratégico de las normas: yo invoco o defiendo una norma o exijo el cumplimiento sólo porque me conviene - no porque esté seguro de su validez. La tercera y más difícil de interpretar es el caso límite de un sistema de normas que es en sí mismo "malo»: rituales satánicos de práctica voluntaria, o como el presidente Ronald Reagan se imaginaba la Unión Soviética: el «imperio del mal» ${ }^{10}$. Y cuarto, el caso que nos interesa aquí bajo la palabra reclamo barbarie: el marchitamiento de una moralidad y la quizás nada espectacular necrosis de normas que fueron operativas en la vida de una sociedad y que nominalmente quizás siguen «existiendo» ${ }^{11}$. Este caso difiere claramente de la anomia de Durkheim, en el sentido de que no son las normas mismas las que acontecen inciertas (y que por esta incertidumbre los actores padecen hasta el extremo de la autodestrucción en un «suicidio anómico», o lo que Parsons denominó "carencia de definición de aquello que es deseable»). Es diferente porque los actores sobrepasan intencionadamente los límites de un sistema de normas perfectamente presente y bien definido o permanecen insensibles a sus demandas. Tratamos aquí con el proceso psicológicamente misterioso - estrictamente hablando con uno imposible ${ }^{12}$ en el cual alguien «intencionadamente olvida algo». La barbarie no se tiene que confundir con la ausencia de normas, porque con la barbarie el punto en cuestión es la práctica negativa de la depreciación, la violación y la subversión de las normas.

Los actos bárbaros, por lo tanto, se pueden definir de la siguiente manera: su resultado es la grave debilitación de la integridad física de individuos o grupos. Y la motivación a la acción surge (en un aspecto negativo) de los actores que se eximen de un deber existente para justificar o explicar sus acciones: por ejemplo, apelan a una «ley de la selva», es decir, al contrario de la ley. A partir de aquí, a esta usurpación por ejercer o tolerar la violencia destructiva, sin justificación, la denominaremos «bárbara» —independiente del perpetrador y del alcance de la destrucción. Los actos y las omisiones «bárbaros» son el resulta-

9. Cfr. Slavoj ZyzeK, Tarrying with the Negative: Kant, Hegel, and The Critique of Ideology, Durham, Duke University Press, 1993.

10. Cfr. La definición filosófica exacta en ibídem 95: "Actos que, aunque "malos" en su contenido, cumplen totalmente los criterios de un acto ético [...] su única motivación es el Mal como principio, razón por la cual pueden involucrar la radical abrogación de los propios [...] intereses, hasta el sacrificio de la propia vida.»

11. Ferenc Fehér y Agnes Heller (Biopolitics, Viena, Avebury, 1994, 97) hacen referencia al «deliberado debilitamiento de las fuerzas de prohibición de la cultura y la historicidad». El problema no es que se están violando las normas, sino que determinadas categorías de acciones se están extrayendo de la esfera de las normas — «las nociones mismas de bueno y malo pierden sus significados» (Zyzek, Tarrying with the Negative, 100).

12. Cfr. Jon Elster. 
do de procesos descivilizantes ${ }^{13}$ en los cuales el «autocontrol» (motivacional) (Norbert Elias) se deja ir ignorando las interdependencias (cognitivas) y las afiliaciones.

\section{Examen del segundo tipo: macrofenómenos y microfenómenos}

No trataré las teorías sociológicas en cuanto a las circunstancias bajo las cuales tienen lugar los fenómenos del segundo tipo, es decir, fenómenos de barbarie interna en la civilización o "posterior» a ésta. La "fuerte» y sugerente hipótesis que trae hasta aquí es, como ya he mencionado más arriba, que la reacción hostil de la civilización contra si misma está programada dentro de la civilización. Si la función de la cultura consideramos que es restaurar la paz, sublimar y regular los instintos, asegurar la reciprocidad y ser racional — sería dudoso que fuera represora. En su lugar debería haber la hipótesis de una paz simulada de civilización, las premisas de la cual están dispuestas de tal manera que la paz se tiene que derrumbar. Que esta clase de regresiones puede tener lugar no está sujeto a debate. Si se demuestra que la hipótesis mencionada es cierta, debe haber defectos estructurales identificables que tienden a convertir la civilización en un programa autosubversivo ${ }^{14}$, haciendo que tengan lugar regresiones con una cierta necesidad - como Short Cuts, la película de Robert Altman. Lo que confundimos con paz de la civilización, en realidad y según esta hipótesis, sería tan sólo una situación de tregua durante la cual los medios y los motivos para romperla se acumulan. ¿¿Describe el proceso de modernización una curva en forma de U?

Después de todo, hasta hace poco estábamos, como ciudadanos de los países de la OTAN, moral y militarmente equipados para la eventualidad condicional de actos de asesinatos masivos organizados por el Estado. Esto era así porque la creíble buena voluntad de utilizar armas nucleares para vengarse parecía el medio apropiado y efectivo para prevenir que la otra parte golpeara primero. La persistencia de condiciones civilizadas dentro del sistema internacional, según el más amplio consenso, evitó así que se recurriera a actos bárbaros como ultima ratio. De este modo, la persistencia de la civilización depende de su apoyo externo, como en un exoesqueleto, por parte de su evidente contrario. De acuerdo con la lógica de la disuasión, es sólo por miedo de un contraataque que no tiene lugar el primer golpe. El contraataque, no obstante, presupone que, tras el primer golpe, la parte afectada estará preparada para padecer una regresión hasta el nivel de aquella radical carencia de escrúpulos que es necesaria si, vacío de todo sentido militar, aún se está dispuesto a aniquilar partes de la población civil del enemigo con armas nucleares estratégicas.

13. MCNNell, «DeCivilizing Procesas», Nacht einmalandersgesehen, Zurich, 1954.

14. Véase también Gehlen, la conclusión del cual es similar - a pesar de sus últimas especulaciones más optimistas sobre la "cristalización cultural». Ata el «progreso de la civilización» a la "pérdida de inhibiciones terribles» y amplía la utopía negativa de "gente moviéndose con una naturalidad azoradora en el espacio de acero de la tecnología». 
(Nunca he entendido cómo - a no ser que sea por una perfecta automatización que excluiría cualquier opción de fuga — se puede asegurar esta expectativa «al otro lado». Pero si esta expectativa de represalia segura no está asegurada, el adversario puede contar con que las inhibiciones morales han quedado intactas, es decir, con la no ocurrencia del contraataque. En este caso, sin embargo, la disuasión perdería su lógica condición previa.) En este escenario, la civilización se mantiene únicamente por la disposición a deshacerse enseguida, en el caso hipotético, de las inhibiciones dictadas por la misma civilización. Y esta disposición no se puede simular, tiene que existir más allá de cualquier duda. En la civilización que compartimos participamos mientras estemos preparados de una manera convincente (por nosotros y para los otros) a renunciar a sus logros en caso de emergencia - dicho de otro modo, a convertirnos en bárbaros.

Cinco criterios convierten al holocausto y a su singularidad de tipo ideal en el paradigma de lo que queremos decir con el término barbarie, en el sentido de ser «interno» a la civilización o "posterior» a ella:

a) Revocación repentina y explícita de

b) estándares altamente desarrollados de civilización mediante

c) el poder estatal terrorista con el

d) resultado de un resuelto y organizado — si bien no guiado por motivaciones militares-

e) asesinato masivo por parte del ejército.

Éste es un caso extremo de barbarie moderna de postcivilización, un caso cuyo drama lo hace destacable y quizás también deslumbrante.

En los macroestados de la naturaleza, el poder estatal mismo, mediante la guerra de agresión y de genocidio, se transforma en el preceptor de una Wolfsmoral y revoca los dictados de la civilidad. También se puede hablar, por contraste, de «microestados de la naturaleza»: la erosión de sistemas informales de normas dentro del mismo proceso de modernización que implican una predisposición a la intolerancia indiferente o a la perpetración oportunista de actos bárbaros de exclusión y violencia.

Creo que hoy en día las formas de racismo, exclusión, descivilización y violencia que no son perpetradas por el Estado tienen más que ver con una comprensión de la relación contemporánea entre modernización, civilización y barbarie. La mayor parte de los fenómenos «bárbaros» que nos preocupan hoy en día no son los importantes sucesos preparados y explicados por los gobiernos (como es el caso de los Khmers Rojos o la dictadura militar argentina), sino la violencia no estatal dentro de una tan sólo supuesta sociedad «civil» y economía civil.

En primer lugar, la violencia desenfrenada e indiscriminada es la marca distintiva del conflicto que tiene lugar no en países con un gobierno intacto, sino en las ruinas contemporáneas de la categoría de estado. En Bosnia, Georgia, Somalia, Líbano y Ruanda los poderes estatales correspondientes, quemados hasta los fundamentos, han dejado el terreno libre para las guerras de bandas. A esto no le podemos llamar "guerras civiles», aunque sólo sea porque el poder 
estatal, el cual podría proteger u otorgar los derechos civiles a las partes, ya no existe. Los actores implicados no son antiguos ciudadanos, sino «no-ciudadanos». Parece como si, hoy en día, la mera persistencia de un poder estatal organizado (incluida la existencia de una cadena de mando militar ininterrumpida) implique, en lugar de un peligro, la garantía de unos estándares mínimos de civilización ${ }^{15}$.

Además, en el corazón de la denominada «vida civil», nos enfrentamos a actos de violencia desmesurados y sin objetivo por parte de quienes están sobrecargados por la exigencia moral de soportar y reconocer diferencias de género, orientación sexual, edad, capacidad física, religión y etnicidad. La protección especial contra los actos violentos que la civilización garantiza para lugares de culto, fieles, niños, moribundos y muertos (todos dentro la categoría de «no-combatientes») ya no se da por hecha. Esta pérdida se evidencia en el tipo de microestados de la naturaleza que no están impulsados ni autorizados por el poder estatal, sino que se dirigen sin ambigüedad contra las intenciones declaradas y los evidentes intereses del estado. En estos casos, el poder estatal sólo participa por su impotencia preventiva y curativa. De modo que:

a) la erosión progresiva del umbral de las inhibiciones, las exigencias morales y las restricciones acostumbradas pueden

b) —independientemente del grado de perfección civil logrado-

c) también ocurrir a actores aparte del poder estatal y sus agentes,

d) pueden basarse en la acción afectiva o en omisiones y

e) pueden, también, tener lugar sin causar víctimas y, sin embargo, mostrar todos los rasgos de las acciones bárbaras.

Considero importante el hecho de que las consecuencias bárbaras se pueden originar no sólo en la acción (racional o efectiva), sino también en la omisión.

Las acciones culpables son (en principio) siempre identificables, porque hay un acto y un perpetrador, mientras que las omisiones culpables no lo son. Si del resultado queremos deducir los autores, nos encontramos en un problema de atribución: ¿Quién debería haber actuado (en lugar de incumplir una acción obligatoria), de qué manera y por su tolerancia indiferente ha contribuido de forma causativa a los resultados?

También me parece importante la distinción establecida entre consecuencias bárbaras derivadas de una aplicación «real» de violencia simbólica o física y las que resultan de la retención de derechos o recursos materiales. Es lo suficientemente evidente que el efecto de la exclusión en el segundo caso - respecto a la calidad y, sobre todo, a la cantidad- no es, en principio, más «inocente» que en el primer caso.

15. Con esta afirmación, me gustaría provocar el desacuerdo (si no la total autocrítica) de aquéllos que, en los debates políticos de la izquierda alemana, complacidos con su propia radicalidad, no hace demasiado tiempo rechazaban categóricamente la legitimidad del «monopolio de la violencia por parte del Estado». 
Partiendo de la base de estos dos perfiles contrastados de características, así como de las dos distinciones antes introducidas, quiero generalizar la siguiente observación: no ha sido hasta el fin de la Guerra Fría que este último perfil de «barbarie» ha acontecido más pertinente para la comprensión de las condiciones contemporáneas, y a la vez más preocupante que el perfil tradicional en que el poder estatal, a través de la acción violenta ejercida deliberadamente, es el autor de consecuencias «bárbaras».

Hay, sin duda, una semántica alemana para el concepto de «barbarie» en cuanto a la guerra nazi de agresión y de conquista y al holocausto. Los esfuerzos para "adaptarse» a estas catástrofes morales colectivas guían, entonces, de forma paradigmática, todas las reflexiones alemanas sobre el concepto de barbarie. Sin embargo, el mundo de fenómenos que incluye este concepto no está —o de ningún modo debería estar — limitado a estos fenómenos, la causa de los cuales se puede reseguir hasta llegar a un ataque del Estado dirigido a las bases de la civilidad y la civilización. Si el concepto de barbarie se emplea como concepto sociológico útil, se debe de mantener abierto para incluir también una serie de fenómenos diferentes, los cuales, con respecto a la calidad (si no al alcance) de las consecuencias, se ajustan bastante bien a sus definiciones. Por encima de todo, aquí nos referimos a fenómenos de la violencia no estatal que también se ajustan a la definición de barbarie, es decir, a la revocación de obligaciones de un antiguo contrato social civilizacional y a la posterior recaída en un «estado de la naturaleza». No hay ninguna razón evidente para que el concepto de barbarie sea reservado para el caso más dramáticamente impresionante, es decir, el sistema nazi y la singularidad de sus crímenes. Las consecuencias de una reserva parecida serían difícilmente aceptables. Si procediéramos de este modo, fácilmente perderíamos de vista los síntomas de la desorganización social; son similares, como mínimo, porque también equivalen a lo que he descrito como «inclusión interna», si bien diferentes, sus formas de causación se pueden comparar a casos de rupturas de civilización apoyadas por el Estado.

\section{Perfil de tres hipótesis sobre la ocurrencia de «microestados de naturaleza»}

El problema que nos preocupa hoy en día es adaptarnos sociológicamente a la erosión de las categorías del «mundo vital» a un nivel micro — moralidad cotidiana, estilo, respeto y decencia, sensibilidad moral, disciplina interiorizada y restricciones sociales_-, siempre que esta erosión pueda comportar consecuencias «bárbaras». Estoy pensando aquí en casos aislados de ruptura de la civilidad que son muy difíciles de explicar y de predecir en términos de categorías estructurales. Su ocurrencia es característicamente dispersa, local y contingente, y cambian rápidamente según el autor, el objeto y la escala. Estos actos $\mathrm{u}$ omisiones no van unidos de una manera evidente a escisiones estructurales de la sociedad. Como mínimo, podemos intentar una cartografía sociológica de estos fenómenos. 
Para construir una tipología de estos incidentes de negación violenta de las ataduras y las obligaciones civilizacionales básicas, nos pueden ser útiles las metáforas topográficas debajo, fuera, y dentro. Con esto quiero decir (1) actos de desocialización a lo largo de una dimensión «vertical»: la exclusión de la pretensión de un derecho "normal» y de una capacidad de participar (actos de exclusión "descendente», marginalización, tratamiento de las otras personas como «superfluas»); (2) una dimensión "horizontal»: exclusión del estatus de ciudadano (migración y discriminación etnonacionalista), y (3) consecuencias similares de formalización y diferenciación societal, lo que da como resultado que esferas enteras de acción y sectores institucionales puedan convertirse en un "país extranjero interno" el uno por el otro: las fronteras entre estos dos sectores institucionales no las puede unir una orientación «civil» compartida. En los tres casos está claro que no es una cuestión de la igualmente inocente constelación "premoderna» de una inclusión social aún no conseguida. Al contrario, lo que encontramos son fenómenos regresivos que implican la "clasificación» de los individuos y grupos y la consiguiente descalificación de los mismos como miembros de lo que en lenguaje parsoniano se denomina la «comunidad societal».

\section{No-integración vertical: marginalización y exclusión de una "nueva subclase»}

Las civilizaciones modernas, debido a sus complejidades técnicas, son vulnerables al comportamiento «incompetente» y se vuelven funcionalmente intolerantes por carencia de competencias básicas que ellas, al mismo tiempo, dejan de generar en el ámbito universal. Establecen condiciones cada vez más exigentes para la participación «normal». Su manera de funcionar se puede comparar a un juego integrado por tres clases de gente: $a$ ) los ganadores, $b$ ) los perdedores y $c$ ) los incompetentes, inelegibles, «superfluos», es decir, los faltos de las precondiciones mínimas de participación. Un ejemplo puede ser la división entre el empleado, el desempleado y el «incapacitado para trabajar». Equilibrar los resultados distribucionales entre $a$ y $b$, dejando así a los perdedores en una posición tolerable, conlleva a menudo la consolidación de las barreras dirigidas en contra de $c$. Las organizaciones industriales modernas y del sector servicios, así como las instituciones educativas, establecen un umbral más bajo por el cual las personas se convierten en, implícitamente, no aptas para el trabajo y para la participación, lo cual las convierte en «incapacitadas para trabajar». La admisión completa al juego parece suponer (como mínimo) los siguientes cinco «puntos esenciales» de la participación social, tanto en términos de mercado laboral como en términos de que se conceda el reconocimiento social de manera más general: trabajar o tener las capacidades que exige el mercado laboral; legalidad (un historial delictivo limpio, permiso de residencia o documentos personales válidos; salud física y mental intacta o recobrable; seguridad social (incluyendo la familia), protección y vivienda, y un nivel lo suficientemente bueno de competencia lingüística y cultural, afinidad étnica incluida). 
Esta tripartición del universo de las oportunidades de la vida subraya y exacerba la diferencia entre "perdedores» y «no aptos». No son los perdedores quienes son marginados, sino los tildados de inadmisibles. Paradójicamente, alguien podría decir: sólo siendo perdedor —en batallas institucionalizadas de distribución, en instituciones formales sanitarias y educativas, en mercados y en las elecciones - ya se sale ganando, porque se tiene el estatus de participante legítimo. Los marginados son los excluidos de la participación: aquéllos que carecen de protección social y familiar, que no han acabado la escuela, incapacitados para trabajar, extranjeros sin residencia o permiso de trabajo («ilegales»), gente con un historial delictivo importante, los discapacitados físicos y mentales, adictos a determinadas drogas ilegales (que en los Estados Unidos parece ser que comienzan a incluir el tabaco). A los miembros de tales categorías sociales les faltan los prerrequisitos de participación -el equivalente sociológico a un carnet de conducir o a unos conocimientos básicos de informática- y son excluidos de participar, en parte o totalmente, en la vida civil. El punto en el que diferentes grados y aspectos de una incompetencia participativa construida socialmente constituyen una "nueva subclase» se está expandiendo, especialmente porque los defectos relacionados con uno de los puntos esenciales antes mencionados implican también otros. Las sociedades modernas, por lo tanto, parecen generar un "cuarto mundo interno» de gente que comparte la situación de unas expectativas de vida irrecuperablemente y acumulativamente menguadas.

\section{No-integración de los "forasteros»: problemas de migración y minoría}

Bajo este encabezamiento, quiero, de manera muy esquemática, explorar algunas combinaciones de características socioestructurales de poblaciones minoritarias (los problemas de «suministro») y la estructura legal y cultural de los países acogedores (la "parte demandada» respondiendo y resolviendo estos problemas). Este ejercicio usará un conjunto de categorías socioespaciales y demográficas que parecen adquirir importancia para el análisis de las estructuras sociales europeas. (Por ejemplo, términos como migración, disparidades interregionales de prosperidad, región, fronteras, proximidad, territorio, patria, población residente, polos de desarrollo, etc.)

Las dos variables socioespaciales mediante las que quiero organizar conceptualmente el campo son, por un lado, la «territorialidad» (en el sentido de residencia heredada y reconocida, vecindario o región) de minorías étnicas dentro la población residente y, del otro, la presencia de un (más o menos lejano o potente) «estado protector» que proporciona recursos políticos y materiales y, si es necesario, la opción de retirada. Si combinamos estas dos dimensiones de forma dicotomizada, resultan cuatro casos (figura 1) de significación muy distinta.

Las celdas separadas de este diagrama designan los casos siguientes: 


\begin{tabular}{|l|l|c|}
\hline & \multicolumn{2}{|c|}{ Territorialidad } \\
& Sí & No \\
\hline Estado Sí & 1 & 2 \\
\hline $\begin{array}{l}\text { Protector } \\
\text { Externo No }\end{array}$ & 3 & 4 \\
\hline
\end{tabular}

Figura 1.

Celda 1: territorio heredado y «fuerte» protección por parte de un país protector (inmediatamente fronterizo) (por ejemplo: la minoría húngara en Rumanía).

Celda 2: dispersión con protección (por ejemplo: los turcos en Alemania).

Celda 3: territorialidad sin protección (por ejemplo: los vascos en España). Ésta es la función de una garantía ejercida por el Gobierno central de un país, dentro del cual vive la minoría (por ejemplo: el estatuto de autonomía español), o por las agencias internacionales.

Celda 4: dispersión sin protección (efectiva): judíos antes de 1949, gitanos; trabajadores emigrantes de fuera de la Unión Europea («extracomunitarios»); fuerza de trabajo asiática en Singapur y en los estados del Golfo; así como refugiados de guerra, guerras civiles en general, y de la pobreza.

La comparación de los cuatro casos muestra que, dentro del ámbito de los procesos globales de migración, el caso 4 representa la categoría de minorías étnicas que, actualmente y previsiblemente, está creciendo más rápidamente.

Ahora bien, la estructura de este problema confronta en cada caso las disposiciones legales del país huésped ${ }^{16}$ y su política cultural, la cual determina la capacidad para resolver problemas. La pregunta esencial aquí es qué tipo de esfuerzos de asimilación se requieren como prerrequisitos para una garantía permanente de derechos de residencia y participación, y a quién se concede estatus de candidato para poder llevar estos esfuerzos a buen término. Dicho de otro modo, la cuestión en juego es el nivel de demandas de asimilación («necesarias/no necesarias») y la capacidad o buena disposición atribuida para asimilar ("posible/no posible»). Aquí, también, quiero dicotomitzar ambas variables y dejar todas las diferenciaciones internas en las cuatro celdas. La asimilación de una población migratoria étnica o minoritaria es vista como se muestra en la figura 2 .

El esquema especifica las siguientes constelaciones y soluciones legales de la parte «receptora»:

16. Con esta categorización, me baso en un ensayo importante de Rainer Bauboeck, «Kulturelle Integration von Einwanderern", Zeitschrift für Sozialforschung, I, 1994: 71-76. 


\begin{tabular}{|l|c|c|}
\hline & no necesaria & necesaria \\
\hline no posible & 1 & 2 \\
\hline posible & 3 & 4 \\
\hline
\end{tabular}

Figura 2.

Celda 1: Secesión o garantía de derechos (fuertes) de autonomía y autogobierno (por ejemplo: Estado español, Bélgica, Canadá; el divorcio de terciopelo entre las repúblicas checa y eslovaca).

Celda 2: Racismo, o toda forma de ius sanguinis, y la regulación de migración y acceso según origen: aquí se exige un alto grado de esfuerzo de asimilación y, al mismo tiempo, parte de la población minoritaria (potencial) es declarada totalmente incapaz de satisfacer esta demanda. Un ejemplo es la ley alemana de ciudadanía y sus fundamentos en el artículo 116 de la Constitución alemana.

Celda 3: Multiculturalismo; llevado a cabo, como máximo, en algunos centros urbanos de algunas antiguas colonias británicas como Sidney y Toronto.

Celda 4: Asimilación, representada, por ejemplo, por el principio de políticas minoritarias francesas.

En principio, y en buena lógica, se podría combinar cada tipo de problema de la figura 1 con cada solución al problema de la figura 2. Aun así, es más empíricamente probable, con respecto a las soluciones, el siguiente orden de prioridades:

El caso 4 de la figura 2 parece empíricamente poco prometedor hoy en día como modelo prescriptivo, como lo demuestra el fin real de la teoría del melting pot de los Estados Unidos, el cual se considera que va camino de ser un «mosaico» y un país bilingüe de facto; allí, y en otros países, la cultura y la lengua «blanca» dominantes ya no parecen lo suficientemente «hegemónicas» como punto de convergencia para la asimilación de minorías migrantes o territoriales.

Caso 3: la capacidad de la mayoría de la población para tolerar el «multiculturalismo» parece estar en gran medida agotada en la mayoría de sociedades del mundo de la OCDE. Esta solución genera claramente síntomas de ansiedad por el estatus entre las poblaciones mayoritarias. Además, dados los patrones predominantes de estratificación étnica y de división del trabajo, y sobre todo cuando se aplican al extracomunitario, la opción del multiculturalismo se teme que trastorne ampliamente el ya precario equilibrio de distribución en los mercados de trabajo, vivienda y escuela.

La variante 1 es, en el mejor de los casos, una posibilidad para minorías territoriales asentadas en territorios compactos, y tan sólo teóricamente para 
poblaciones de minorías étnicas con signos de dispersión ${ }^{17}$, como es el caso de la figura 1.

Desde esta lógica de sustracción, surge una cierta gravitación en lo que respecta al caso 2 de la figura 2: a los «extranjeros» se les exige y a la vez se les declara incapaces de asimilación —el doble vínculo del racismo. En el mejor de los casos, esta aproximación está mitigada por formas «estiradas» de 4 - es decir, la naturalización completa sólo para miembros de la segunda generación que han crecido en el país huésped. Estas consideraciones y las estimaciones de probabilidades generales sugieren que la constelación menos deseable - la que conlleva, con toda probabilidad, consecuencias «bárbaras»— es a la vez la más probable, es decir, la combinación del caso 4 de la figura 1, y el caso 2 de la figura 2.

\section{No-integración "desde dentro»: ¿modernización como programa autosubversivo?}

Las conceptualizaciones de «modernidad» y «modernización» por parte de los historiadores y los científicos sociales han llevado a la identificación de tres tendencias seculares de desarrollo:

a) La expansión social simultánea y la especialización real de los mercados: juegos de doux commerce, crecimiento y sumas positivas. Todo el mundo puede comprar y vender, pero, al mismo tiempo, no todo se puede comprar o vender (por ejemplo: despachos públicos, esposas, salvación espiritual, esclavos, exención del servicio militar, permisos de residencia, etc.).

b) Igualdad (ante la ley, en la participación política): prohibición de exclusión y discriminación en el ámbito del estado nacional y la ciudadanía que aquél otorga y protege.

c) La propagación de la racionalidad científica como legitimación última de la acción y la profesionalización, es decir, la institucionalización de las pretensiones de verdad y las exigencias de competencia profesional dentro de la cultura cognitiva de las sociedades modernas. También aquí podemos ver la coincidencia de la generalización social — se puede entrenar todo el mundo para sostener verdades - con una especialización esencial: las pretensiones de verdad sobre el buen gusto o el significado de la vida se vuelven inadmisibles.

En todas partes la modernización política empieza con la introducción de los hasta ahora «extranjeros» (a partir de aquí, bárbaros en el viejo sentido) en un sistema de estatus interno. Los «salvajes» se hacen (políticamente) súbditos de la corona y (económicamente) esclavos potenciales. Para ilustrarlo, recordemos el año 1542 cuando Bartolomé de las Casas triunfó en los tribunales

17. Comparad los proyectos de los regímenes autoritarios para establecer un "estado judío» en la Patagonia, en Madagascar o simplemente en el Este. 
españoles en su disputa teológica con Sepúlveda. Se estableció que, a partir de entonces, los habitantes originarios de las colonias que estaban bajo la Corona española tendrían, al menos, el estatus de candidatos al plan divino de salvación. A partir de entonces, se les atribuyó la calidad de tener alma y, por lo tanto, serían idóneos para convertirse a la fe religiosa y, con ello, compartir los sacramentos. Con el establecimiento de su estatus político, económico y teológico, los «salvajes» entraron a compartir una mínima ciudadanía. En cualquier caso, desde entonces ya no eran un nullum o un objeto, sino propietarios de un estatus que se podía desarrollar igual que la regulación de las modalidades de su inclusión.

La neutralización de las diferencias, legal —y en parte económica- y acumulativa, era la lógica que guiaba el proceso de modernización política en el camino hacia el constitucionalismo, la democracia liberal y el estado del bienestar: en todas sus manifestaciones, esta modernización significa que, dentro de las fronteras de los estados nacionales, las diferencias cada vez se declaran más legalmente irrelevantes. La lógica «inclusiva», que constituye el núcleo normativo de la civilidad y la ciudadanía, implica el deber del estado (y, en el extremo inferior, de "todos») de tolerar, abstraerse de e ignorar la alteridad de los otros. El precepto es tratar las diferencias reales entre ciudadanos en contextos específicos como intranscendentes ${ }^{18}$. Hoy en día se cuestiona si hay limitaciones legítimas a este "deber cívico de abstraerse», puesto que parece una exigencia que, por razones psicológicas y culturales, se puede percibir como "excesiva» y «agobiante». ¿ Hay algún punto en el que la ampliación de las demandas y las garantías legales a las categorías sociales, hasta ahora subordinadas o excluidas, comporte síntomas de estrés y sobreesfuerzo por parte de aquéllos que pierden ventajas y privilegios relativos? ${ }^{19}$. ¿Qué provoca que las exigencias morales y políticas de «neutralizar diferencias» sean insoportables, y para quién lo son?

Allí donde los defensores de la modernización política declaran intranscendentes las diferencias, provocan, evidentemente, reacciones en las que los actores individuales y colectivos se retiran de sus supuestos «deberes de abstraerse» y recurren a la rebiologización de la diferencia y a la denegación de la inclusión legal (y a fortiori: económica). El estado nacional republicano, la emigración masiva hacia el norte de América, la emancipación judía, la expropiación de la aristocracia y la abolición de la esclavitud en los estados del sur de los Estados Unidos fueron — casi de forma simultánea a mediados del siglo XIX- las condiciones del contexto histórico para el surgimiento del racismo moderno, dis-

18. «La modernidad hizo el gran sacrificio, al menos de palabra, de no hacer distinciones por el color de la piel [...] El orden democrático es anónimo, sin marca, sin nombre» (Fehér y Heller, Biopolitics, 93, 97).

19. Mennell («Decivilizing Processes», 211) trata en este contexto la hipótesis que «la atadura entre la complejidad estructural y los "controles civilizadores" sobre el comportamiento de la gente es curvilíneo [y] que quizás más allá de un cierto punto genera bolsas de anonimidad metropolitana dentro de las cuales las reservas externas sobre los impulsos y [...] también la eficacia de las presiones hacia el autodominio disminuyen». 
frazado de biologismos. Su mensaje es el de la garantía de la diferencia ${ }^{20}$. Afirma que es irracional (porque es realmente imposible) desestimar las diferencias hasta donde la ley y la constitución exigen. Aquello que se exige legalmente se declara biológicamente imposible. Las fronteras de las naciones y las del estatus social, que, como tales, han demostrado ser ineficaces y penetrables a través de los derechos legales y la movilidad social, eran ahora sustituidas, y a la vez reafirmadas, por unos recientemente creados límites biológicos realmente «indiscutibles», puesto que eran ratificados de manera incontrovertible por las autoridades en ciencias naturales. El racismo declara que abstraerse de determinadas diferencias es un disparate y es absurdo; en sus versiones «izquierdistas» y populistas, en cambio, apela a la neutralización política de aquellas diferencias que pueden ser vencidas, es decir, las diferencias económicas dentro de un étnicamente homogéneo Volksgemeinschaft. Hay numerosos indicios que sugieren que, en vista de la unificación europea y tras el fin de las diferencias hasta entonces garantizadas por el Telón de Acero, hoy nos volvemos a encontrar con una virulenta demanda social y política de "garantía de la diferencia", con un llamamiento populista a favor de decisiones que reivindiquen las fronteras y de legitimaciones que limiten el acceso, la igualdad de derechos y las demandas de bienestar social a categorías de personas etiquetadas como «extranjeros».

La insistencia en políticas exclusivistas indica que la garantía de la igualdad de derechos y la abstracción legal de las diferencias (de cultura, de estatus, de ingresos) sigue siendo un camino del todo precario de la civilización. Desde luego, este camino no es inmune a la formación de reacciones xenófobas y racistas, especialmente para los perdedores del juego de la distribución (así como para aquellos ganadores que adeudan su posición a la protección exclusiva); en vista de las perspectivas de fronteras penetrables, hay razones racionales para el pánico de estatus. Estos sentimientos de pánico son activados tanto por la percepción de apertura de nuevas viviendas y mercados de trabajo, como por la apertura a nuevos discursos y prácticas culturales.

Se podría señalar, después de todo, que los fundamentos legales de las modernas medidas inclusivas y de los derechos de los ciudadanos no han sido debilitados de manera significativa. Pero el «deber civil de abstraerse» no se puede reforzar sólo a través de medios legales. Éste es el talón de Aquiles de la modernidad política, la cual garantiza y exige de los ciudadanos la igualdad de derechos pese a la diferencia. Las obligaciones de abstraerse de esta diferencia, si es que han de convertirse en válidas, tienen que ser reconocidas e impuestas sobre los ciudadanos en sus vidas diarias. Este reconocimiento es estorbado por intereses distributivos (por ejemplo: intereses en la defensa de recursos y en la defensa de discursos y terrenos culturales). El peso de estos intereses hace que no parezca demasiado prometedor confiar en los medios

20. Muchos actos de violencia «menores» se pueden interpretar según este modelo de "garantía de la diferencia»: el atacante "sólo quiere averiguar/mostrar quién es el más fuerte aquí» o dónde acaban los derechos que el atacante reclama para sí mismo mientras los niega a aquél a quien él ataca. 
«suaves» de educación y habituación. Cada acto de reclamación de la libertad civil de uno mismo y, a fortiori, cada acto de reclamación de derechos positivos para la protección social, precisa de la tolerancia de «todos los otros». Hasta el punto de que si esta tolerancia se rehúsa o bien el peso de la tolerancia se exagera y se declara insoportable, la validez operativa de estos derechos quedará pisoteada — pese a la letra de la ley.

La ya mencionada tripartición de las sociedades modernas en ganadores, perdedores y los realmente descalificados para participar — que podría, por cierto, aplicarse a la economía política internacional- implica dos líneas de demarcación: la superior, a lo largo de la cual tienen lugar los conflictos distributivos institucionalizados, y la inferior, a lo largo de la cual tienen lugar las batallas por el reconocimiento, la asistencia y la inclusión. Cuando tienen lugar actos bárbaros de descivilización y exclusión en cualquier sitio estructuralmente identificable, es en cualquiera de las líneas, o de un lado al otro de la línea inferior de demarcación. Es decir, tanto las víctimas como los perpetradores de actos bárbaros son esta gente o grupos (quizás también países: Irak antes de la Guerra del Golfo o Serbia tras el colapso de Yugoslavia servirían como ejemplos) que más probablemente se dejen llevar por el pánico y la incertidumbre respecto a si "aún" pertenecen a los perdedores o "ya» pertenecen a los parias. El intento violento de "garantizar la diferencia» respecto a algún «mundo externo» parece particularmente tentador para quienes se ven en peligro de ser degradados definitivamente, como sugieren los estudios de casos de skinheads de la Alemania del Este y de los radicales de extrema derecha. Por comparación, aquéllos que están seguramente situados por encima de la línea de demarcación superior - los miembros de las económicamente y políticamente seguras clases medias y los de sus movimientos sociales- están cultivando una retórica de la civilidad y del universalismo que extrañamente es políticamente ineficaz. No es ni siquiera sencillo decidir si la moderna manifestación de barbarie indica un incremento real de estos fenómenos o si constituyen un efecto de la observación, debido a las agudizadas sensibilidades morales de los miembros de la clase media y de los medios de comunicación.

Mientras el incumplimiento del «deber de abstraerse» sea pasivo y suceda por omisión, el umbral de la barbarie será difícil de determinar. Esto se podría calibrar determinando la validez huidiza de aquello que Axerod ha denominado «metanormas». Por ejemplo, la norma «no matarás» corresponde a la metanorma: "te ofenderás ante la violación de esta norma», en este caso, ante los actos de asesinato ${ }^{21}$. Las condiciones «posmodernas» de la

21. Al respecto, la «internalización» de la disciplina, enfatizada por Elias, también pide que, en caso de fracaso de aquel control interno, subsidiariamente entren en acción otros controles; el mismo procedimiento de control interno tiene que ser aprobado externamente. Cuando los actores tienen razones para pensar que éste no será el caso y que la violación de las normas no será vengada ni por la desaprovación social de los curiosos, entonces el esfuerzo de «internalización» pierde su motivo en «mí» y está tan lejos como haría falta suponer por lo que respecta al «resto de personas». 
sociedad desacreditan aparentemente nuestra disposición a protestar o a sentirnos ofendidos. Podemos especular con la idea de que el debilitamiento de las metanormas afecta a la validez de normas primarias de manera paralela - caso de un sabotaje pasivo de los estándares de, por ejemplo, las relaciones internacionales civilizadas, como ya sucedió en el infame fracaso de los estados de Europa y de Norteamérica por poner fin a los bárbaros acontecimientos de la guerra de Bosnia. Diferentes de la tolerancia cínica y pasiva de los actos bárbaros cometidos por otros son las formas activas de barbarie, aquéllos cometidos contra otros y que consisten en la violación de la integridad física y simbólica de categorías de otros seres humanos. Es aquí donde empieza el «microestado» de la naturaleza de la violencia bárbara, o de la disposición para una violencia de esta envergadura. Esta versión moderna de barbarie no suele suceder por instigación del poder estatal; más bien al contrario, indica que parte de la sociedad ha hecho una regresión por debajo de los principios nominalmente proclamados por cualquier poder estatal moderno constituido.

Se puede reaccionar a estos fracasos del poder estatal y de los principios de ciudadanía en el que se fundamentan haciendo la observación - tan popular estos días entre hilos comunitarios de razonamiento- que los defensores de la política de modernización basada en la modernización política universalista se han embarcado en un proyecto político que, para empezar, ya no es realista. Están desperdigando la promesa engañosa de una vida moralmente menos exigente, en la que no hay razón para agotar imprudentemente la capacidad propia de soportar la diferencia. La referencia a "ciertas» comunidades que excluyen los derechos individuales y que atan a los individuos en las comunidades, tradiciones y territorios que ellos no han escogido libremente, y en las fronteras de los cuales dejan de existir las obligaciones de soportar las diferencias, es, no obstante, una proposición que me parece peligrosa desde un buen principio, y parece poco realista en su resultado esperado. Es peligrosa porque el riesgo de intensificación, en el decurso de la cual las fronteras de una determinada «moralidad local» se trazan cada vez más adentro, se acepta de manera implícita. Y es poco realista porque el comercio internacional, la movilidad y la globalización cultural son fuerzas societales contra las cuales las porosas fronteras exteriores de las «comunidades» ofrecen poca resistencia. En consecuencia, parece que no hay demasiada esperanza de escapar del dilema de la modernidad política aparte de convocar las fuerzas legales, políticas y morales de la civilidad, el fracaso de las cuales seguro que dará lugar a una violencia extendida de muchos, pequeños y dispersos estados postcivilizacionales de la naturaleza.

La ley por sí misma no garantiza el cumplimiento universal de los estándares de la civilidad. Tan sólo establece las exigencias y los principios que se han de implementar (en un grado discutiblemente creciente) fuera del terreno de la legislación y la jurisprudencia, es decir, en la práctica cotidiana de la vida social. En efecto, la ley trata a todo el mundo por igual, pero no a todas las esferas de la vida ni a todos los tipos de demandas o violaciones de las 
demandas. No todas las situaciones e interacciones están cubiertas por la ley o son del todo accesibles a un establecimiento efectivo de la ley y a la aplicación de sus normas: la violencia doméstica, el acoso sexual en el trabajo y el núcleo de decisiones de la dirección empresarial son, en gran parte, espacios extralegales - o espacios en que la misma iniciación de procedimientos y sanciones legales puede ser sancionada extralegalmente. Estos «límites a la justicia» hacen referencia a dos circunstancias recíprocas: por un lado, el acceso limitado de la justicia a los actores y sus precarias interacciones y, por el otro, el acceso limitado de los actores a la justicia (por ejemplo: niños y gente dependiente, clientes). La eficacia de los derechos puede ser minada por sanciones negativas y positivas, así como por la amenaza, la promesa o incluso la anticipación de aquellas sanciones. Si es éste el caso, el efecto protector se vuelve, entonces, un objeto de comercio (como ocurre con la protección legal contra el despido, que, en caso de conflicto, no "protege», se convierte en un mercado para la cancelación «voluntaria» del contrato de trabajo). Una «limitación» más a la «justicia formal» la encontramos allí donde la aplicación real de los derechos es prohibitivamente cara en términos de dinero y/o tiempo.

Por lo tanto, los derechos no traen incorporada un aura de su reconocimiento, y no predisponen automáticamente a la adopción de los deberes correspondientes. Su efecto «educativo» es, también, precario hasta el punto que su "positividad» se refleja. La "positividad» conlleva una aguda conciencia de fluidez por parte del ciudadano y cliente de la ley, es decir, del hecho que las estipulaciones legales eran diferentes ayer y lo volverán a ser probablemente mañana, según la constelación política. El aura de reconocimiento y de obligaciones se torna también más precario a través de las leyes de la «formalidad»; el reflejo del hecho que su validez no tiene lugar automáticamente, sino que es el resultado de procesos formales y textos a menudo muy elaborados. Además, como es bien sabido, las demandas hechas por la vía de la legalidad formal son, para algunos, más fáciles de cumplir que para otros, y más fácil en algunas áreas que en otras. Las características de positividad y formalidad aumentan la distancia entre las normas sociales y las legales y las obligaciones que respectivamente les corresponden. De este modo, la positivización detallada y la formalización de las normas sociales pueden perjudicar a la validez real, abrir espacio al estratégico uso de las normas y abrir así rendijas de integración social, es decir, grietas entre la validez nominal y la real de la ley, que no se podrán volver a cerrar sólo mediante la ley.

El efecto civilizador de los derechos depende de la habilidad y de la disposición de los sujetos a la ley para ejecutar sus órdenes y su significado de forma espontánea e informal. Las normas habituales de la moralidad civil, reconocimiento mutuo, tolerancia, respeto, disposición al compromiso, empatía y cooperación son aquellos «hábitos del corazón» y componentes del "capital social» en los que la ley se tiene que apoyar con el fin de regular con eficacia un orden social civil. Sin estos fundamentos interiores de la 
vida civil, la justicia formal no es pacificadora, sino que, al contrario, puede agravar el conflicto ${ }^{22}$.

Por otra parte, es característico de la sociedad «moderna» desalentar estructuralmente la actitud de asumir la responsabilidad y de practicar las virtudes antes mencionadas. Siempre hay "otro", asumimos cómodamente nosotros, que se puede hacer cargo, que es un «experto», o "las autoridades» o, incluso, «todos los otros». El resultado es un tipo de segundo analfabetismo respecto a la cooperación cívica como fenómeno de masas, bien sea debido a problemas de acción colectiva no resueltos, o bien a la propia incompetencia. Así, la burocracia, la competencia de base científica y el profesionalismo pueden contribuir a la infrautilización crónica de la competencia cívica diaria, y finalmente al agotamiento de este recurso, que —al igual que las capacidades humanas en general- tiene tendencia a desvanecerse si no se utiliza con regularidad.

La pregunta es: ¿Bajo qué circunstancias puede la interacción social que tiene lugar por medios especializados como el dinero, la ley o el conocimiento experto, compensar esta variedad de efectos secundarios potencialmente descivilizantes? Las teorías liberales asumen, como respuesta a esta pregunta, que la erosión de las virtudes cívicas se detendrá automáticamente por mecanismos que generan integración social como subproducto de la interacción sistémica: a medida que se incrementa la interacción comercial, se incrementa el sentido de «simpatía» y de obligación mutua entre los socios comerciales. Como la asunción de este automatismo parece un poco ingenua y arriesgada hoy en día, la erosión de competencias y virtudes cívicas básicas sólo se podrá parar cuando los ciudadanos sean conscientes de las peligrosas implicaciones de esta erosión y cuando, además, haya estructuras asociativas capaces de inspirar una actitud "deliberativa» y escéptica hacia los subproductos desintegradores y potencialmente «bárbaros» del proceso de modernización legal, científica y económica. Estas estructuras asociativas de obligación mutua y de cooperación son, al mismo tiempo, minadas por poderosas fuerzas de «racionalidad formal»: ley, dinero y conocimiento profesional sugieren la idea errónea de que se ha hecho aquello que era necesario si se ha pagado el precio, se ha cumplido la ley, se ha buscado el consejo profesional o se ha actuado competentemente. Sin embargo, si algo va mal, no se puede culpar a nadie. La «virtud civil» deviene una categoría residual:

22. Esto ya se ha hecho evidente en el simple caso de los derechos de igualdad para la libertad de expresión. No lo pueden practicar, lógicamente, todos aquéllos que están presentes simultáneamente, pero sólo en aquella secuencia civilizada y moderada y en una duración que, a la vez, casi no se puede formalizar legalmente. El orden legal no solamente presupone determinados estándares informales en la microgestión del uso real de los derechos, sino que también puede contribuir a la erosión de estos estándares concediendo la ventaja legal a aquéllos que no cumplan con estos estándares informales. Un caso respecto a ello es el siguiente: "Los jueces de un juzgado de distrito de Flensburg [han] concedido a los miembros de un grupo de turistas una reducción de los gastos porque se les estropearon las vacaciones al ver a un conjunto de huéspedes discapacitados en el restaurante del hotel» (Frankfurter Rundschau, 18 de mayo de 1994). 
reina un minimalismo moral, y todo aquello que rebase sus límites se considera supererogativo, no demandable.

Las sociedades «modernas» son aquéllas que engendran diferencia en las tres dimensiones consideradas aquí (debajo, fuera, dentro). Nuestra interacción diaria con la gente está guiada mutuamente por la premisa de que lo más probable es que no les volvamos a tratar. Estas diferencias hacen mucho más difícil reconocer la afiliación bajo condiciones de estrés y conflicto. Con esta perspectiva de proliferación de la diferencia, la fidelidad a las virtudes cívicas se hace más exigente y necesita más esfuerzos. Cumplimos con nuestros deberes si lo hacemos, no hacia los buenos vecinos, sino hacia extraños. Como de hecho éste es el caso, lo más arriesgado se convierte en la expectativa de su acción recíproca. Como todos los participantes saben que éste es el caso, el resultado de esta conciencia puede ser una espiral descendente de renuncia a la interacción, de indiferencia, y de una comunicación más especializada, con la posibilidad cada vez más decreciente que los juegos se transformen en juegos de garantía. Zygmunt Bauman ${ }^{23}$ escribe sobre la tendencia del proceso de modernización a «degradar, censurar y deslegitimar las motivaciones éticas de la acción social [...] El proceso de civilización es, entre otras cosas, un proceso de renuncia al uso y al despliegue de la violencia del cálculo moral, y de emancipación de la racionalidad de la interferencia de las normas éticas y las inhibiciones morales».

Por lo tanto, en las sociedades modernas hay un aumento de la necesidad - pero, al mismo tiempo, un descenso del suministro- del recurso no renovable, o el «capital social» ${ }^{24}$, de la autocoordinación cooperativa y del reconocimiento social. Haciendo cabida al espacio que hay entre los dos, encontramos el potencial para la barbarie moderna.

23. Zygmunt Bauman, Modernity and the Holocaust, Oxford, Polity Press, 1989, 29.

24. Cfr. "el instante clásico» (Robert D. Putnam, Making Democracy Work: Civic Traditions in Modern Italy, Princeton, Princeton University Press, 1993). 